\title{
The Relationships among Quality of Online Education, Learning Immersion, Learning Satisfaction, and Academic Achievement in Cooking-Practice Subject
}

\author{
Yae-Ji Kim ${ }^{1}$ and Seung-Hoo Lee ${ }^{2, *}$ \\ 1 School of Global Studies, Kyungsung University, Busan 48434, Korea; yaeji76@ks.ac.kr \\ 2 School of Hospitality and Tourism Management, Kyungsung University, Busan 48434, Korea \\ * Correspondence: pingklo123@ks.ac.kr; Tel.: +82-51-663-5971
}

Citation: Kim, Y.-J.; Lee, S.-H. The Relationships among Quality of Online Education, Learning Immersion, Learning Satisfaction, and Academic Achievement in Cooking-Practice Subject.

Sustainability 2021, 13, 12152. https://doi.org/10.3390/ su132112152

Received: 6 October 2021

Accepted: 31 October 2021

Published: 3 November 2021

Publisher's Note: MDPI stays neutral with regard to jurisdictional claims in published maps and institutional affiliations.

Copyright: (c) 2021 by the authors. Licensee MDPI, Basel, Switzerland. This article is an open access article distributed under the terms and conditions of the Creative Commons Attribution (CC BY) license (https:/ / creativecommons.org/licenses/by/ $4.0 /)$.

\begin{abstract}
The purpose of this study was to identify the problems of online education perceived by learners in a time when non-face-to-face online lectures are conducted due to the spread of COVID19 , and suggest measures to improve educational outcomes. Therefore, the structural influence of cooking practice on the quality of online lessons, learning immersion, learning satisfaction, and the achievement felt by learners was verified. The sample of the study was a college student majoring in cooking, and a total of 509 responses were used for analysis. The results of the study are as follows: First, it was analyzed that there was a significant influence on learning immersion in the order of content, interaction, and educational environment among the quality of online classes. Second, among the quality of online classes, class content and educational environment showed positive (+) influence on learning satisfaction. Third, learning immersion and learning satisfaction showed a positive influence on academic achievement. Fourth, in the direct effect of online class quality on academic achievement, it was analyzed that only class content had a positive (+) effect. Based on the results of this study, the provision of learning materials with detailed explanations was suggested in the online cooking practice class rather than providing a simple cooking video. In addition, it was suggested that as a way to improve academic achievement of online education, it is necessary to provide content that allows learners to immerse themselves in class, as well as class content and educational environment, and consider learning satisfaction.
\end{abstract}

Keywords: learning immersion; learning satisfaction; quality of online class; academic achievement; cooking-practice subject; COVID-19

\section{Introduction}

Due to the COVID-19 global pandemic, gatherings and movement between people have been restricted and all patterns of daily life have been curtailed [1]. This new phenomenon of life has had an impact on all fields-such as society, culture, economy, and education. Universities have also embraced related technologies in the face of pandemic and started providing online education to students without time and space limitations [2]. Online lectures have the advantage of being able to learn at a place and time suitable for the learner's situation, and interactivity where teachers and learners can share knowledge wherever the internet is available [3]. Online classes are divided into real-time online classes and non-real-time online classes according to the simultaneity of teaching-learning among members [4]. In the field of higher education, the development and sharing of open course content has become an important issue. The US has been operating MOOC platforms such as Coursera, Udacity, and edX in 2012, and Korea has been a K-MOOC service since 2015 [5]. As such, online education has been implemented for several years in the past, but since it has been applied to all education fields due to COVID-19, the educational satisfaction of learners is negative. The reasons for the decrease in educational satisfaction include difficulties in interactive communication between instructors 
and learners, deepening educational inequality, and the need to establish a communication network due to simultaneous access [6]. The instructors' online learning methods include watching e-learning classes, watching recorded videos, downloading lecture materials, using other video content, and real-time on-line classes [7]. The survey on satisfaction with online education after COVID-19 is as follows. In a survey conducted in early April of 14,000 undergraduate and graduate students through niche.com, a website evaluating schools and universities in the United States, $67 \%$ said online lectures were not as effective as face-to-face lectures [8]. In Korea, a recent survey of university students found that more than $70 \%$ of respondents were not satisfied with non-face-to-face classes, and $56 \%$ answered that adequate measures for online education in the future were not properly prepared. Accordingly, some Korean university students are requesting a partial refund of tuition fees, taking leaves of absence or dropping out.

The preceding studies on online education are as follows. Research before COVID-19 has dealt with topics of education such as cyber universities, K-MOOC, and e-learning, but in recent studies, various topics about the rapidly changing educational environment are being studied. Lee, Zae, and Youn [9] analyzed the limitations of instructors and learners and suggested strategies to overcome them. Kim [10], Lee, and Jeong [11], Lim and Lee [12] conducted research to improve the quality of classes by exploring factors affecting learning satisfaction and achievement in online education. Additionally, Lee, Park, and Yun [13], Jeong and Yun [14], Jung and Yoon [15] identified issues and suggested improvement directions through recognition and case analysis of online class experiences by major. Although various studies have been conducted on university education since the outbreak of COVID-19, it is difficult to find studies on the quality and performance of online education focusing on cooking practice subjects. The South-Korean government has announced plans to foster a non-face-to-face edutech industry in preparation for the postCOVID-19 era [7]. The emergence of the COVID-19 strain virus makes it difficult to predict the end of the pandemic, so online classes are expected to continue. However, the process of converting all lectures into online lectures is causing a lot of difficulties and confusion for both instructors, learners, and operators [13]. In particular, cooking-related subjects, which require skill proficiency through practice, have many limitations in achieving learning goals only through online education. Most cooking practice lectures require functional learning through the active physical activities of students rather than learning through theory. In order to operate a non-face-to-face online class, the instructor in charge has limitations in the process of preparing, executing, and evaluating the online class, because it is a lecture that takes a very large portion of the time to perform the physical activity.

Accordingly, this study aims to identify the problems of online education from the learner's perspective and suggests improvement directions by confirming the structural impact relationship on the quality of online lessons of cooking practice education and the sense of achievement felt by learners for college students. Furthermore, through the verification of the mediating effect by learning immersion and learning satisfaction, it is intended to suggest ways to improve educational outcomes by comparing the influence on academic achievement.

\section{Literature Review}

\subsection{Quality of Online Education}

Online classes are a form of education that are conducted for the purpose of transferring knowledge and use communication tools connected to the internet and the web [16,17]. It has not been long since online education was introduced as an educational method, however there is no agreed definition [18]. Therefore, online classes are also called distance learning, e-learning, computer-mediated learning, blended learning, cyber learning, and web-based learning [19]. Online classes are conducted in two ways: synchronous and asynchronous environments [4,20]. The Korean Ministry of Education divides the types of remote classes into three main categories: 'real-time interactive', 'content utilization type' and 'task-oriented performance type'. The real-time online class system allows learners to 
enter a professor's classroom at a designated time, take classes, and discuss the content of the class in real time [21]. Most systems are accessible to at least 1000 people at the same time, and learners and professors can have instant feedback and interaction [22]. Skyler [23] stated that learners' satisfaction with real-time classes is higher than that of text-based online classes. For real-time online classes, only people who create meeting rooms need to register and invitees include Cisco Webex, Zoom, Google Meet, and Microsoft Teams which can participate only by knowing the internet address [21].

The non-real-time online class system is divided into instructive and active classes. First, in the case of the instructive class, the learner learns with the specified content or recording lecture, and the professor gives the learning progress and feedback. Active classes are conducted by watching learning content and also by remote discussion through messenger and comments. Both systems are in the form of learners learning designated lectures in non-real-time and conducting activities later. Lectures are sometimes produced by professors themselves or use various forms of educational materials related to learning, such as YouTube. In addition, to ensure the learners' right to study, the appropriate amount of classes should be secured according to the class time [15].

Delone and Mclean [24] presented information quality, system quality and service quality as important variables for the success of information systems, and since then, quality factors have often been used to determine the success of online classes. The key factors affecting the quality of online classes offered by universities should be evaluated in terms of student satisfaction, and the factors affecting student satisfaction are information quality, service quality, and system quality [25]. Chei and Lee [26] defined the quality of the class as the quality level that learners perceive for the learning environment, interaction, and class content.

As such, factors related to classes, such as the educational content and learning environment experienced by students in classes, are drawing attention [27]. Therefore, this study defined the quality of classes as class content (information quality), student-professor interaction (service quality), and online learning environment (system quality) based on studies such as Lee and Lee [25], Chei and Lee [26], Jeong [28]. Information quality refers to the quality of teaching design aspects such as the content of online classes and delivery methods and strategies, and service quality is a subjective evaluation that is recognized and judged by users. System quality refers to the technical level of accuracy and efficiency of the system [25]. Previous studies on online lectures are as follows.

For studies conducted before COVID-19, the effect of university e-learning information, service, and system quality on learner satisfaction and achievement was analyzed [25,29-31]. Research conducted after COVID-19 has focused on learning satisfaction and achievement in online education [32-35].

However, there are a number of educational quality measurements and satisfaction surveys on online education in theoretical subjects, but it is difficult to find those focused on practical subjects. Therefore, this study aims to analyze the effect between the quality of non-face-to-face online education, immersion, satisfaction, and cognitive academic performance, focusing on the cooking practice subjects of universities after COVID-19.

\subsection{Learning Immersion}

Csikszentmihalyi $[36,37]$ suggests that immersion is an intrinsic motivation construct in the sense that it is an intrinsically rewarding experience that does not require any external reward or goal other than the action itself. They also investigated that people experience immersion when perceived challenges and perceived abilities are balanced. Immersion can be divided into nine dimensions: clear goals, instant feedback, personal skills appropriate for a given challenge, integration of actions and consciousness, potential control sense, focus on tasks, loss of self-awareness, distortion of time sense, and selfobjective experience [38]. Early studies have defined immersion by measuring the time that learners are actually involved in a learning task [39], however, more recently it is referred to as the intensity of concentration, effort, and interest shown by learners [40], and 
it is defined as the quality of effort to focus on learning outcomes that learners want to achieve [41]. It is very important for learners to control and immerse themselves in their learning processes [42], because of the limited direct interaction with professors and the limited degree and immediacy of communication [43]. Thus, immersion in online lectures is one of the main factors for learners to achieve self-directed learning.

\subsection{Learning Satisfaction}

Satisfaction can be defined as a "total state of mind that is caused by a combination of emotions generated by a mismatch between the customer's actual experience and expectations and feelings before the purchase experience" [44]. Learning satisfaction means the degree of overall satisfaction after the learner has learned, determined by their evaluation of educational services or by the quality of the program [45].

Astin [46] has suggested that satisfaction is a subjective response to learners' educational experiences. Shin and Chan [47] conceptualized it as the degree to which an individual learner perceives a positive correlation between the learning process taken and the learner's individual learning experience. Kim and Kang [48] have suggested that learning satisfaction can help improve and reflect future programs as an indicator that can clearly show whether or not educational goals have been achieved. For Lee and Lee [26], Lee [49], and Park [50], satisfaction is one of the most important factors in discussing training performance, and is used as a variable in defining learning effectiveness.

\subsection{Cognitive Academic Achievement}

Academic achievement is often used in the field of education to assess the effectiveness of education [51]. Academic achievement is the result of the acquisition of learners changes, developmental levels, knowledge, and skills, as a result of education [46], whether learners have a realistic implementation of learning and specific performance of learning content [52]. For Kim and Chung [53], it is an objective indicator that can measure learning performance, defined to the extent that we understand the learning content we obtain through training programs and achieve our learning goals. In particular, adult learners have a variety of educational experiences to judge the learning experience and have the ability to evaluate learning content [54]. Therefore, in this study, cognitive academic achievement is the subjective evaluation of what the learner themselves recognize about the learning activities performed.

Pace [55] proposed the use of self-reporting methods because there is no significant difference between the self-reporting method and the actual measured achievement score, and it shows consistency as a measurement tool. Jeon and Kim [56] also validated the feasibility by requiring learners to measure self-aware attitude changes, knowledge growth, and technology improvements for learning evaluation. Therefore, this study aims to measure academic achievement by measuring the self-reporting method of the learner's own subjective judgment, which can replace objective indicators.

\section{Methodology}

\subsection{Research Model and Hypotheses}

Lee and Lee [25], Chei and Lee [26], Lee, Kim, and Kim [30] use the information system success model proposed by Delone and Mclean [24] to identify important factors that determine the success of online classes and used as a measure to evaluate quality.

The quality of instruction was composed of information quality (class content), service quality (interaction), and system quality (learning environment), and was set as a preceding variable to measure learning satisfaction and learning outcomes. 
Based on theoretical considerations and prior research on each variable, this study designed a research model such as Figure 1 to verify the relationship between quality of non-face-to-face online education (information quality, service quality, system quality) and learning immersion, learning satisfaction, and cognitive academic performance.

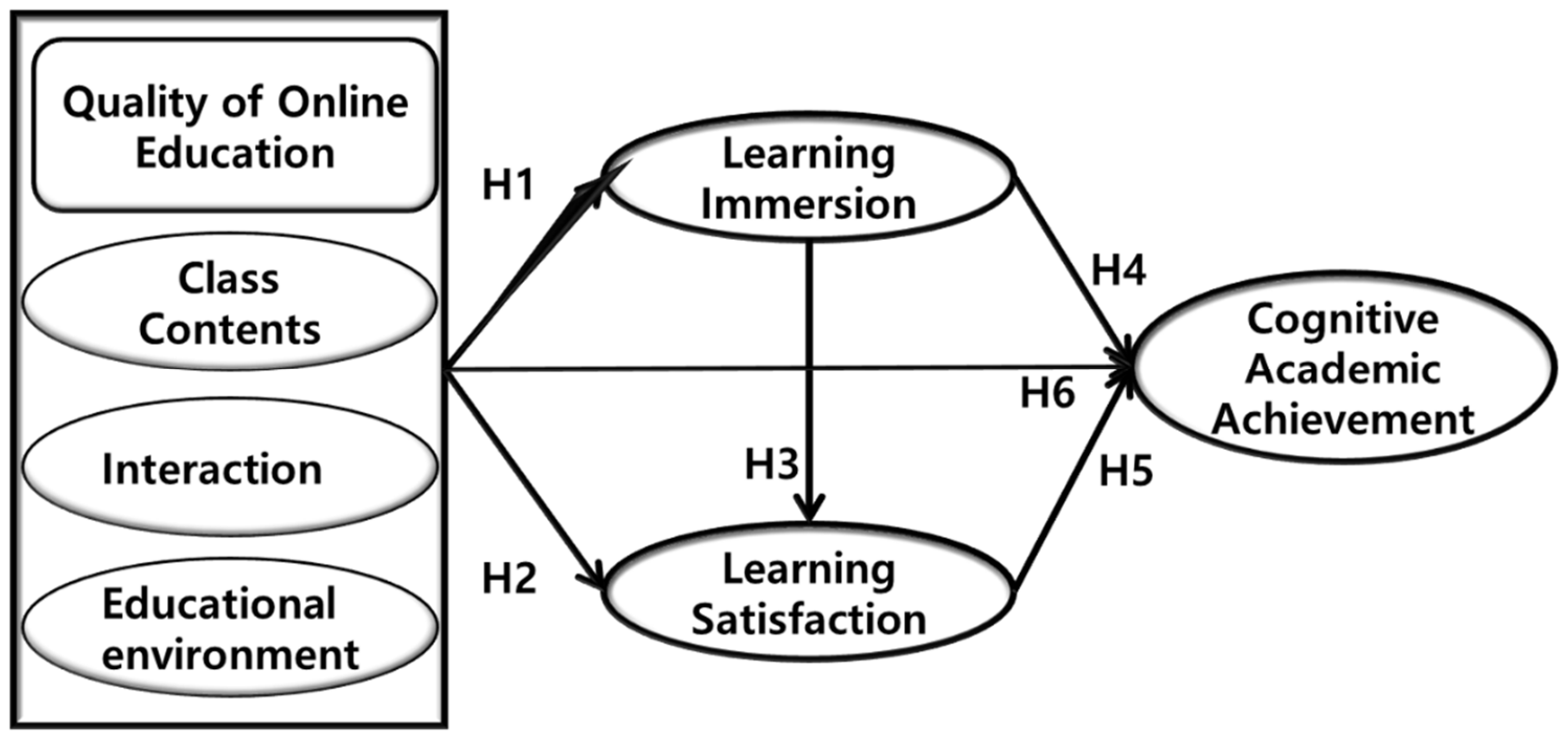

Figure 1. Research model.

\subsection{Hypotheses}

\subsubsection{Quality of Online Education and Learning Immersion}

In a study by Kim, Shin, and Kim [29], ease of use, interaction quality, self-control, and computer efficacy showed significant impact relations with learning immersion, but lecture quality and lecture content did not show significant impact. Kim, Roh, and Yu [57] verified the impact on learning immersion by dividing content quality into information quality (class content), service quality (interaction), and system quality (learning environment). As a result, it was confirmed that information quality (class content) was statistically significant with learning immersion. Ahn and Shin [58] studied the effect of non-face-toface education quality on learning immersion and educational satisfaction for students majoring in tourism, showing static influence on learning immersion in the order of quality of education content, professor's reliability, and professor's response. Choi and Ahn [35] showed the positive effects of learning immersion in the order of quality of education programs, quality of instructors, educational environment, and quality of interaction. Based on prior research, Hypothesis 1 was established to verify the impact relationship between the quality of the class and learning immersion.

Hypothesis 1 (H1). The quality of online classes will have a significant impact on learning immersion.

\subsubsection{Quality of Class and Learning Satisfaction}

Lee and Lee [25], Chei and Lee [26], Lee, Kim, and Kim [30] used it as a measure to assess the quality of classes as an important factor in identifying the success of online classes. The quality of the class consisted of the contents of the class, interaction, and learning environment, and was set as a variable to measure the learning satisfaction. As a result of the study, the contents of the class showed the greatest impact on learning satisfaction. A study on the effect of the culinary education service quality of the lifelong education center on the satisfaction of adult learners showed a significant effect on satisfaction in the order of reliability, certainty, and tangibility [59]. Kim, Choi, and Ma [60] showed that 
educational programs, educational environment, and educational services significantly affect satisfaction of quality of education services for students at cooking schools. Based on these studies, Hypothesis 2 was established to verify the impact relationship between the quality of the class and learning satisfaction, and to check the difference between online classes and face-to-face classes.

Hypothesis 2 (H2). The quality of online classes will have a significant impact on learning satisfaction.

\subsubsection{Learning Immersion and Learning Satisfaction}

Kim and Um [61] validated that the higher the learner's degree of immersion, the higher the satisfaction of the learning content, from the perspective of the cognitive experience of taking e-learning. Kim, Roh, and Yu [57] have confirmed that learning immersion has a static impact on learning satisfaction by verifying the relationship between learning immersion and learning satisfaction. Huh [62] confirmed the mediated effects of learning satisfaction and learning immersion in verifying the relationship of content quality in university online classes and the intent of learning continuity, and derived that learning immersion has a static impact on learning satisfaction. Thus, Hypothesis 3 is established to verify the relationship between learning immersion and learning satisfaction.

Hypothesis 3 (H3). Learning immersion will have a significant impact on learning satisfaction.

\subsubsection{Learning Immersion and Academic Achievement}

Kim, Shin, and Kim [29] confirmed that learning immersion has a static impact on academic performance, and validated that learning immersion has a mediated effect on learning performance. Choi and Ahn [35] found that learning commitment had a positive $(+)$ effect on academic achievement in the study of the relationship between educational service quality, learning immersion, and academic achievement in non-face-to-face learning. Studies in various fields have verified that learning immersion has a positive effect on academic achievement [63-65]. Thus, Hypothesis 4 is established to verify the relationship between learning immersion and academic achievement.

Hypothesis 4 (H4). Learning immersion will have a significant impact on academic performance.

\subsubsection{Learning Satisfaction and Academic Achievement}

In the studies of Ko, Kim, and Kim [27], Lee and Kim [17], Lee and Lee [12], academic achievement showed a high correlation with learning satisfaction, and academic achievement was set as an exogenous variable to measure learning satisfaction, proving that its influence is significant. In addition, various studies have established hypotheses to investigate the relationship between learning satisfaction and academic achievement $[9,31,33,66]$. Thus, Hypothesis 5 was established to consider whether learning satisfaction would have a significant impact on cognitive academic performance.

Hypothesis 5 (H5). Learning satisfaction will have a significant impact on cognitive academic performance.

\subsubsection{Quality of Class and Cognitive Academic Achievement}

A study was conducted on the effect of e-learning lecture quality on learning performance, and as a result of the analysis, it was verified that there is a positive relationship on learning performance in the order of interaction quality, lecture quality, and content quality [29]. Lee and Seo [31] validated the structural relationship between the quality of classes, learning satisfaction, and academic performance in remote education, confirming that the content of classes and the quality of service operations had a significant impact on academic performance. In addition, a number of studies were conducted to verify the indirect effects of mediating variables, such as learning commitment and learning satisfaction, on the influence of class quality on academic achievement. Kim and Park [33] 
conducted a study on K-MOOC students, demonstrating that the quality of instruction has a positive effect on academic achievement through learning satisfaction as a medium. Choi and Ahn [35] used learning commitment as a mediating variable in a study on the effect of non-face-to-face education service quality on academic achievement, and confirmed the positive impact relationship. Therefore, Hypothesis 6 was established to verify the influence of the quality of online cooking classes on cognitive academic achievement, and to confirm the mediating effect of learning immersion and learning satisfaction.

Hypothesis 6 (H6). The quality of online classes will have a significant impact on cognitive academic achievement.

\subsection{Research Instrument}

The questionnaire for hypothesis testing consisted of 31 questions based on previous research, and 18 questions about the quality of online education (8 questions for class content quality, 5 questions for interaction quality, 5 questions for educational environment quality), 4 questions for learning commitment, 5 questions for learning satisfaction, and 4 questions for cognitive academic achievement. Among them, 3 questions that hindered the validity and reliability were removed through a preliminary investigation.

In addition, 3 observational variables were removed to improve intensive validity and model fit for the finally collected 509 samples, and the questionnaire items used in the analysis of this study were 25 questions. A total 2 demographic questions (by gender, school type) and 4 questions about the experience of taking a non-face-to-face online lecture (number of courses taken, teaching methods, learning tools, computer literacy) are combined to determine the characteristics of the survey respondents. This consisted of 31 final questions. The questions are on a 5-point Likert Scale with 1 point for "not at all", 2 points for "no", 3 points for "normal", 4 points for "yes", and 5 points for "very much". The operational definition of all items and the source and detailed composition of the measured variables are summarized in Table 1.

\subsection{Data and Sample}

The sample of the study was conducted with university students who had experienced taking non-face-to-face online courses in cooking practice due to COVID-19 in 2020. The scope of the cooking practice courses included cuisines such as Korean, Western, Chinese, and Japanese, but also all practical subjects related to cooking such as baking, coffee making, and food and beverage skills. For the survey, a total of 100 preliminary surveys were conducted from 30 July to 10 August 2020 using the Google online questionnaire, and it was determined that there were no major problems in verifying the hypothesis through factor analysis and reliability verification. Therefore, a total of 550 survey responses were collected by adding 450 copies from 20 August to 14 October 2020. Among them, a total of 509 copies were used for the survey, excluding 22 copies of the sample that did not respond to some questions and 19 copies of unfaithful responses. AMOS 23.0 and SPSS 25.0 statistical programs were used, and the hypothesis was verified through descriptive statistics analysis, confirmatory factor analysis, and structural equation model analysis. 
Table 1. Constructs and items included in the questionnaire.

\begin{tabular}{|c|c|c|c|}
\hline & uct & Operational Definition/Measurement & Reference \\
\hline \multirow{6}{*}{$\begin{array}{l}\text { Quality } \\
\text { of } \\
\text { On-line } \\
\text { Education }\end{array}$} & \multirow[b]{2}{*}{$\begin{array}{l}\text { Class } \\
\text { Contents } \\
(\mathrm{CC})\end{array}$} & $\begin{array}{c}\text { Information quality in terms of instructional design, such as the content of the online class, } \\
\text { delivery method }\end{array}$ & \multirow{6}{*}{$\begin{array}{l}\text { DeLone \& McLean [24] } \\
\text { Lee \& Lee [25] } \\
\text { Jeong [28] } \\
\text { Lee, Kim \& Kim [30] } \\
\text { Chei \& Lee [26] } \\
\text { Kim \& Lee [32] }\end{array}$} \\
\hline & & $\begin{array}{l}\text { (CC1) Clarity of class objectives } \\
\text { (CC2) Appropriateness of learning objectives } \\
\text { (CC3) Adequacy of the amount of learning } \\
\text { (CC4) Systematic content of classes } \\
\text { (CC5) Expectations and agreements for class content, } \\
\text { (CC6) Providing appropriate learning materials }\end{array}$ & \\
\hline & \multirow[b]{2}{*}{$\begin{array}{l}\text { Interaction } \\
\quad(\mathrm{IN})\end{array}$} & Communication between instructor and student & \\
\hline & & $\begin{array}{l}\text { (IN1) Handling the needs of learners, } \\
\text { (IN2) Communication between instructor and learner, } \\
\text { (IN3) Instructor's active problem solving } \\
\text { (IN4) Fast and accurate feedback from instructors }\end{array}$ & \\
\hline & \multirow[b]{2}{*}{$\begin{array}{l}\text { Educational } \\
\text { Environment } \\
\quad(\mathrm{EE})\end{array}$} & $\begin{array}{l}\text { The level of technical and physical environment as the accuracy and } \\
\text { efficiency of the online education system }\end{array}$ & \\
\hline & & $\begin{array}{l}\text { (EE1) Ease of access to the site, } \\
\text { (EE2) No video stuttering or noise } \\
\text { (EE3) Ease of system menu configuration, } \\
\text { (EE4) Appropriateness of tools for interaction }\end{array}$ & \\
\hline \multirow{2}{*}{\multicolumn{2}{|c|}{$\begin{array}{l}\text { Learning } \\
\text { Immersion } \\
\quad(\mathrm{LI})\end{array}$}} & Level of concentration and intensity of interest in online learning & \multirow{2}{*}{$\begin{array}{c}\text { Marks [40] } \\
\text { Kim, Shin \& Kim [29] } \\
\text { Choi, Yeo \& Jeong [64] } \\
\text { Lee, Kim \& Lee [65] }\end{array}$} \\
\hline & & $\begin{array}{l}\text { (LI1) Class time seems to be passing quickly } \\
\text { (LI2) You can concentrate on taking classes in a private space, } \\
\text { (LI3) Lesson content is interesting in being immersed in the classroom }\end{array}$ & \\
\hline \multirow{2}{*}{\multicolumn{2}{|c|}{$\begin{array}{l}\text { Learning } \\
\text { Satisfaction } \\
\quad(\text { LS) }\end{array}$}} & To assess the degree of satisfaction on the online activities subjectively & \multirow[b]{2}{*}{$\begin{array}{l}\text { Lee [49] } \\
\text { Kim \& Kang [48] } \\
\text { Lee \& Kim [17] } \\
\text { Park [50] }\end{array}$} \\
\hline & & $\begin{array}{l}\text { (LS1) Overall satisfaction with education content, } \\
\text { (LS2) Overall satisfaction with the teaching method, } \\
\text { (LS3) Satisfaction with professionalism in learning activities, } \\
\text { (LS4) Satisfaction with the appropriateness of the learning level, } \\
\text { (LS5) Overall satisfaction with online lectures }\end{array}$ & \\
\hline \multirow{2}{*}{\multicolumn{2}{|c|}{$\begin{array}{c}\text { Cognitive } \\
\text { Academic } \\
\text { Achievement } \\
\quad \text { (CAA) }\end{array}$}} & $\begin{array}{c}\text { Perceptions about the learning outcomes achieved and the recognition that students can succeed } \\
\text { themselves for online learning }\end{array}$ & \multirow{2}{*}{$\begin{array}{l}\text { Eom, Wen, \& Ashill [4] } \\
\text { Barzilai \& Blau [66] } \\
\text { Jeon \& Kim [56] }\end{array}$} \\
\hline & & $\begin{array}{l}\text { (CAA1) Learn a lot through class, } \\
\text { (CAA2) Understand the class content well } \\
\text { (CAA3) Online learning helps me }\end{array}$ & \\
\hline \multirow{2}{*}{\multicolumn{2}{|c|}{$\begin{array}{l}\text { Demographic } \\
\text { Characteristics }\end{array}$}} & Number of subjects & Lee, Seo \& Lee [67] \\
\hline & & Learning place, Learning tool, Computer literacy, gender, grade & Lee [68] \\
\hline
\end{tabular}

\section{Results}

\subsection{Characteristics of Sample}

Students who have taken courses in cooking practice are shown in Table 2. By gender, there were 269 male students (52.8\%) and 240 female students (47.2\%). The types of schools were 366 students $(71.9 \%)$ as college students and 143 students $(28.1 \%)$ as university students. As for the number of courses related to cooking practice, 42 students $(8.3 \%)$ took 1 course, 83 students (16.3\%) took 2 courses, 205 students (40.3\%) took 3 courses, and 179 students (35.1\%) took 4 or more courses. As for the online class method, 313 students $(61.5 \%)$ of the blended classes that combine real-time and non-real-time online lectures accounted for the majority, followed by 128 real-time online classes $(25.1 \%)$ and 68 nonreal-time online classes $(13.4 \%)$. As for online learning tools, laptops accounted for half with 272 students $(53.4 \%)$, followed by desktop-135 students (26.5\%), smartphones68 students (13.4\%), and tablet PC-30 students (5.9\%).

According to the survey on computer skills, 79 students (15.5\%) felt inadequate, 293 (57.6\%) felt average, and 137 (26.9\%) felt proficient.

\subsection{Confirmatory Factor Analysis and Reliability Analysis}

The results of a confirmatory factor analysis to validate the theoretical model are shown in Table 3 below and visualized in Figure 2. 
Table 2. General characteristics of the subject.

\begin{tabular}{|c|c|c|c|c|c|c|c|}
\hline \multicolumn{2}{|c|}{ Characteristics } & \multirow{2}{*}{$\begin{array}{c}\mathbf{N} \\
269\end{array}$} & \multirow{2}{*}{$\begin{array}{c}\% \\
52.8\end{array}$} & \multicolumn{2}{|c|}{ Characteristics } & \multirow{2}{*}{$\begin{array}{c}\mathbf{N} \\
366\end{array}$} & \multirow{2}{*}{$\begin{array}{r}\mathbf{\%} \\
71.9\end{array}$} \\
\hline \multirow{2}{*}{ Gender } & male & & & \multirow{2}{*}{ Type of school } & college & & \\
\hline & female & 240 & 47.2 & & university & 143 & 28.1 \\
\hline \multirow{4}{*}{ Number of taking lecture } & 1 & 42 & 8.3 & \multirow{4}{*}{ Online class method } & blended & 313 & 61.5 \\
\hline & 2 & 83 & 16.3 & & real-time online & 128 & 25.1 \\
\hline & 3 & 205 & 40.3 & & non-real-time online & 68 & 134 \\
\hline & 4 or more subjects & 179 & 35.1 & & & & \\
\hline \multirow{5}{*}{ Learning tools } & desktop & 135 & 26.5 & \multirow{5}{*}{ Computer skill } & & 20 & 3.9 \\
\hline & laptop & 272 & 53.4 & & low & 59 & 11.6 \\
\hline & tablet PC & 30 & 5.9 & & average & 293 & 57.6 \\
\hline & smartphone & 68 & 13.4 & & high & 102 & 20.0 \\
\hline & etc. & 4 & 0.8 & & very high & 35 & 6.9 \\
\hline
\end{tabular}

Table 3. Confirmatory Factor Analysis.

\begin{tabular}{|c|c|c|c|c|c|c|c|c|}
\hline \multirow{2}{*}{ Factors } & \multirow{2}{*}{ Items } & \multicolumn{2}{|c|}{ Estimate } & \multirow{2}{*}{ S.E. } & \multirow{2}{*}{$t$-Value } & \multirow{2}{*}{ C.R. } & \multirow{2}{*}{ AVE } & \multirow{2}{*}{ Cronbach's $\alpha$} \\
\hline & & B & $\beta$ & & & & & \\
\hline \multirow{6}{*}{$\begin{array}{l}\text { Class Contents } \\
\text { (CC) }\end{array}$} & CC 1 & 1.000 & 0.812 & & & \multirow{6}{*}{0.945} & \multirow{6}{*}{0.740} & \multirow{6}{*}{0.925} \\
\hline & CC 2 & 1.029 & 0.841 & 0.046 & 22.459 & & & \\
\hline & CC 3 & 1.131 & 0.873 & 0.048 & 23.739 & & & \\
\hline & CC 4 & 0.993 & 0.785 & 0.049 & 20.342 & & & \\
\hline & CC 5 & 1.017 & 0.826 & 0.047 & 21.875 & & & \\
\hline & CС 6 & 1.052 & 0.789 & 0.051 & 20.502 & & & \\
\hline \multirow{4}{*}{$\begin{array}{l}\text { Interaction } \\
\quad \text { (IN) }\end{array}$} & IN 1 & 1.000 & 0.848 & & & \multirow{4}{*}{0.921} & \multirow{4}{*}{0.743} & \multirow{4}{*}{0.893} \\
\hline & IN 2 & 1.011 & 0.827 & 0.044 & 22.971 & & & \\
\hline & IN 3 & 0.969 & 0.828 & 0.042 & 22.999 & & & \\
\hline & IN 4 & 0.930 & 0.787 & 0.044 & 21.233 & & & \\
\hline \multirow{4}{*}{$\begin{array}{l}\text { Educational } \\
\text { Environment } \\
\text { (EE) }\end{array}$} & EE 1 & 1.000 & 0.769 & & & \multirow{4}{*}{0.904} & \multirow{4}{*}{0.733} & \multirow{4}{*}{0.876} \\
\hline & EE 2 & 1.058 & 0.813 & 0.055 & 19.113 & & & \\
\hline & EE 3 & 0.952 & 0.801 & 0.051 & 18.796 & & & \\
\hline & EE 4 & 1.012 & 0.814 & 0.053 & 19.145 & & & \\
\hline \multirow{3}{*}{$\begin{array}{l}\text { Learning Immersion } \\
\qquad(\mathrm{LI})\end{array}$} & LI 1 & 1.000 & 0.839 & & & \multirow{3}{*}{0.896} & \multirow{3}{*}{0.742} & \multirow{3}{*}{0.883} \\
\hline & LI 2 & 0.962 & 0.813 & 0.045 & 21.454 & & & \\
\hline & LI 3 & 1.000 & 0.880 & 0.042 & 23.951 & & & \\
\hline \multirow{5}{*}{$\begin{array}{l}\text { Learning } \\
\text { Satisfaction } \\
\text { (LS) }\end{array}$} & LS 1 & 1.000 & 0.881 & & & \multirow{5}{*}{0.949} & \multirow{5}{*}{0.789} & \multirow{5}{*}{0.940} \\
\hline & LS 2 & 1.009 & 0.899 & 0.034 & 29.824 & & & \\
\hline & LS 3 & 0.921 & 0.839 & 0.036 & 25.873 & & & \\
\hline & LS 4 & 0.998 & 0.852 & 0.038 & 26.642 & & & \\
\hline & LS 5 & 1.021 & 0.883 & 0.036 & 28.722 & & & \\
\hline \multirow{3}{*}{$\begin{array}{c}\text { Cognitive } \\
\text { Academic } \\
\text { Achievement } \\
\text { (CAA) }\end{array}$} & CAA 1 & 1.000 & 0.892 & & & \multirow{3}{*}{0.916} & \multirow{3}{*}{0.785} & \\
\hline & CAA 2 & 0.849 & 0.819 & 0.035 & 24.229 & & & 0.891 \\
\hline & CAA 3 & 1.005 & 0.861 & 0.038 & 26.582 & & & \\
\hline
\end{tabular}

$\chi^{2}=655.9496(\mathrm{df}=260), p<0.001, \mathrm{CMIN} / \mathrm{DF}=2.523, \mathrm{RMR}=0.025 \mathrm{GFI}=0.903, \mathrm{AGFI}=0.878, \mathrm{NFI}=0.942, \mathrm{RFI}=0.933, \mathrm{IFI}=0.964$ $\mathrm{TLI}=0.959, \mathrm{CFI}=0.964, \mathrm{RMSEA}=0.055$.

First, the convergent validity test is a measure of how well observations can account for the latent variables, judging that the standardization coefficient $(\beta)$ value is 0.5 or higher, the composite reliability $(\mathrm{CR})$ value is 0.7 or higher, and the average variance extraction (AVE) is 0.5 or higher. As a result of the validation of the potential factors, 
the standardization coefficient $(\beta)$ was 0.769 to 0.899 , the AVE value was 0.733 to 0.789 , and the composite reliability (CR) was 0.896 to 0.949 . All factors exceeded the standard value, so it can be said that convergent validity was secured. In addition, the reliability verification of the measurement concept was validated with the Cronbach's $\alpha$, a reliability analysis of the measurement tool based on the internal consistency method, in a way that determined exactly and consistently from the survey respondent. In general, a Cronbach's $\alpha$ of 0.7 or higher can be considered appropriate when checking reliability. According to the results, the Cronbach's $\alpha$ is 0.925 , in the contents of the lecture, the Cronbach's $\alpha$ is 0.893 in interaction, the Cronbach's $\alpha$ is 0.876 in educational environment, the Cronbach's $\alpha$ is 0.883 in learning immersion, the Cronbach's $\alpha$ is 0.940 in learning satisfaction, and the Cronbach's $\alpha$ is 0.891 in cognitive academic performance. Therefore, all five factors were found to be above the standard of 0.7 , indicating that they were reliable. Moreover, the fit of the model is $\chi^{2}=655.9496(\mathrm{df}=260), p<0.001, \mathrm{CMIN} / \mathrm{DF}=2.523, \mathrm{RMR}=0.025$ $\mathrm{GFI}=0.903, \mathrm{AGFI}=0.878, \mathrm{NFI}=0.942, \mathrm{RFI}=0.933, \mathrm{IFI}=0.964 \mathrm{TLI}=0.959, \mathrm{CFI}=0.964$, RMSEA $=0.055$. It shows the common fit indices, recommended values, and analytical results for measurement model. According to the results, all the model-fit indices exceeded the respective common acceptance levels [69], indicating that the measurement model exhibited a good fit with the data collected.

\subsection{Correlation Analysis and Validity Analysis}

As a result of analyzing the degree of correlation between latent variables in confirmatory factor analysis, class content and interaction $(\mathrm{r}=0.845, p<0.001)$, interaction and educational environment $(\mathrm{r}=0.843, p<0.001)$, learning Satisfaction and academic achievement $(\mathrm{r}=0.836, p<0.001)$, learning commitment and academic achievement $(\mathrm{r}=0.805$, $p<0.001$ ) showed high interrelationships in order. Therefore, by checking the degree of correlation between each factor, it can be inferred that there may be a significant influence between factors.

In addition, the discriminant validity of determining whether there is a difference between latent variables should be that the squared values of all correlation coefficients are less than the lowest AVE [70]. In this study, the squared value of the highest correlation coefficient was 0.714, which was lower than the lowest AVE value of 0.733, ensuring discriminant validity. As it can be seen in Table 4 , the average variance extraction is presented in a diagonal direction for easy determination of discriminant validity, and the numerical value in parentheses is expressed as the coefficient of determination $\left(\mathrm{r}^{2}\right)$.

Table 4. Correlation Analysis.

\begin{tabular}{|c|c|c|c|c|c|c|c|}
\hline & $\mathbf{M} \pm \mathbf{S D}$ & $\mathrm{CC}$ & IN & $\mathrm{EE}$ & LI & LS & CAA \\
\hline $\mathrm{CC}$ & $3.73 \pm 0.73$ & 0.740 & & & & & \\
\hline IN & $3.74 \pm 0.74$ & $\begin{array}{c}0.845 \\
(0.714)^{* * *}\end{array}$ & 0.743 & & & & \\
\hline $\mathrm{EE}$ & $3.70 \pm 0.74$ & $\begin{array}{c}0.804 \\
(0.646)^{* * *}\end{array}$ & $\begin{array}{c}0.843 \\
(0.711)^{* * *}\end{array}$ & 0.733 & & & \\
\hline LI & $3.31 \pm 0.83$ & $\begin{array}{c}0.697 \\
(0.486)^{* * *}\end{array}$ & $\begin{array}{c}0.720 \\
(0.518)^{* * *}\end{array}$ & $\begin{array}{c}0.707 \\
(0.500)^{* * *}\end{array}$ & 0.742 & & \\
\hline LS & $3.66 \pm 0.82$ & $\begin{array}{c}0.793 \\
(0.629)^{* * *} \\
\end{array}$ & $\begin{array}{c}0.728 \\
(0.530)^{* * *}\end{array}$ & $\begin{array}{c}0.729 \\
(0.531)^{* * *}\end{array}$ & $\begin{array}{c}0.779 \\
(0.607)^{* * *}\end{array}$ & 0.789 & \\
\hline CAA & $3.63 \pm 0.80$ & $\begin{array}{c}0.777 \\
(0.604)^{* * *}\end{array}$ & $\begin{array}{c}0.738 \\
(0.545)^{* * *}\end{array}$ & $\begin{array}{c}0.722 \\
(0.521)^{* * *}\end{array}$ & $\begin{array}{c}0.805 \\
(0.563)^{* * *}\end{array}$ & $\begin{array}{c}0.836 \\
(0.699)^{* * *}\end{array}$ & 0.785 \\
\hline
\end{tabular}

Note: ${ }^{* * *} p<0.001$. For easy verification of discriminant validity, AVE are presented in a diagonal direction. 


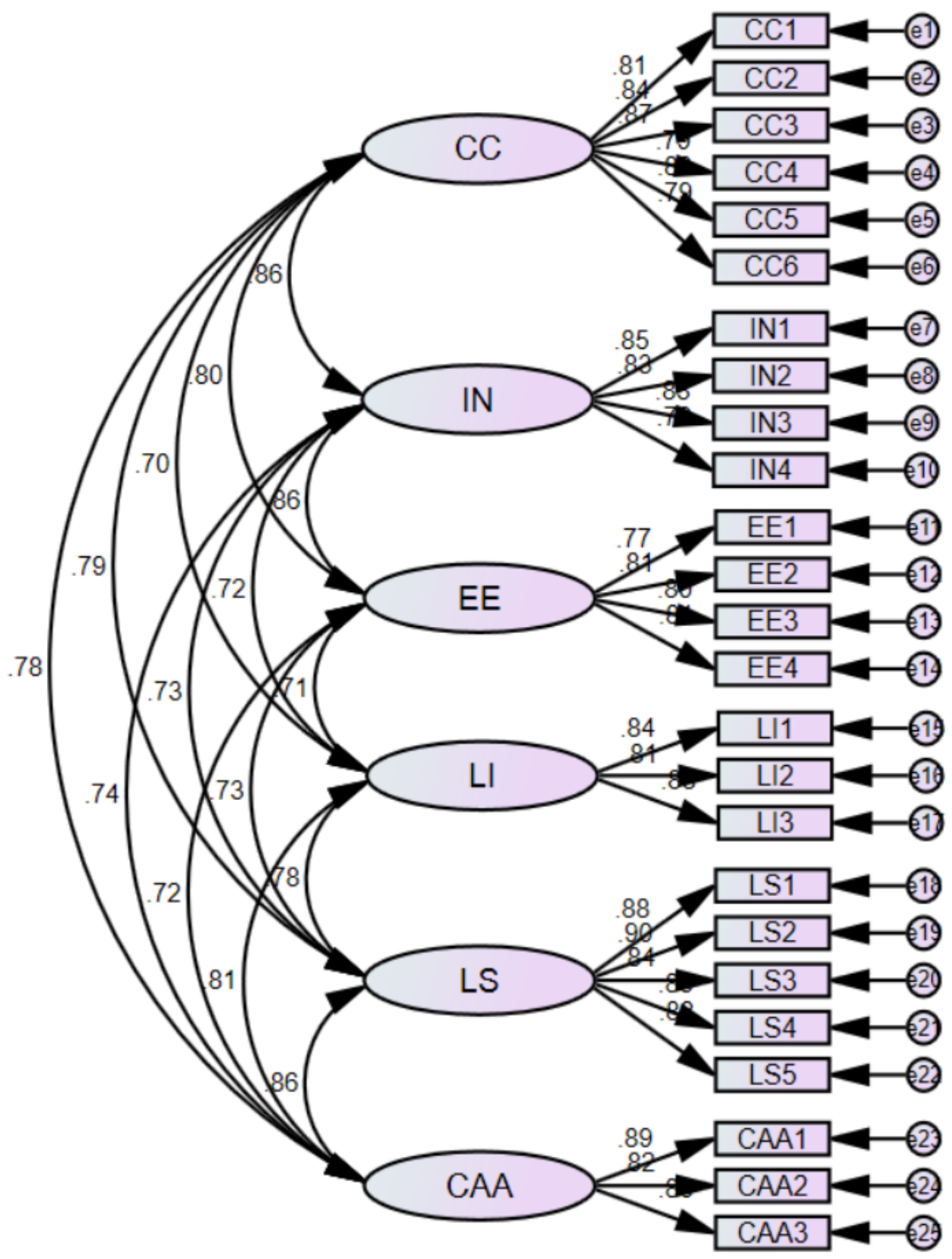

Figure 2. Results of CFA.

\subsection{Results of the Hypotheses Verification}

In this study, structural equation models (SEM) test each relationship between independent and dependent variable. Table 5 and Figure 3 present the results of SEM, showing whether each path is supported or not.

Reported model fit statistics were $\chi^{2}=569.7968(\mathrm{df}=258), p<0.001, \mathrm{CMIN} / \mathrm{DF}=2.209$, $\mathrm{RMR}=0.023, \mathrm{GFI}=0.914, \mathrm{AGFI}=0.892, \mathrm{NFI}=0.950, \mathrm{RFI}=0.942$, and $\mathrm{IFI}=0.972, \mathrm{TLI}=0.967$, $\mathrm{CFI}=0.972, \mathrm{RMSEA}=0.049$.

The path analysis for hypothesis verification is as follows. As a result of the verification of Hypothesis 1 , the quality of online class content $(\beta=0.246, t=2.655, p<0.01)$, interaction ( $\beta=0.235, t=1.969, p<0.05)$ educational environment $(\beta=0.313, t=3.216, p<0.01)$ were analyzed to have a significant influence on learning commitment.

As a result of the verification of Hypothesis 2 , online class quality $(\beta=0.517, t=6.618$, $p<0.001)$, educational environment $(\beta=0.163, t=2.062, p<0.05)$ showed positive $(+)$ 
influence on learning satisfaction. The interaction $(\beta=-0.184, t=-1.688)$ was analyzed to have no significant influence relationship.

Table 5. Results of the Structural Equation Model.

\begin{tabular}{|c|c|c|c|c|c|c|c|c|}
\hline & \multirow{2}{*}{\multicolumn{2}{|c|}{ Hypotheses }} & & \multicolumn{2}{|c|}{ Estimate } & \multirow{2}{*}{ S.E. } & \multirow{2}{*}{$t$-Value } & \multirow{2}{*}{ Result } \\
\hline & & & & B & $\beta$ & & & \\
\hline H 1-1 & $\mathrm{CC}$ & $\rightarrow$ & LI & 0.299 & 0.246 & 0.113 & $2.655 * *$ & Supported \\
\hline H 1-2 & IN & $\rightarrow$ & LI & 0.259 & 0.235 & 0.132 & $1.969 *$ & Supported \\
\hline H 1-3 & $\mathrm{EE}$ & $\rightarrow$ & LI & 0.376 & 0.313 & 0.117 & $3.216^{* *}$ & Supported \\
\hline Н 2-1 & $\mathrm{CC}$ & $\rightarrow$ & LS & 0.639 & 0.517 & 0.097 & $6.618^{* * *}$ & Supported \\
\hline H $2-2$ & IN & $\rightarrow$ & LS & -0.184 & -0.164 & 0.109 & -1.688 & Rejected \\
\hline Н 2-3 & $\mathrm{EE}$ & $\rightarrow$ & LS & 0.200 & 0.163 & 0.097 & $2.062 *$ & Supported \\
\hline H 3 & LI & $\rightarrow$ & LS & 0.424 & 0.416 & 0.052 & $8.197^{* * *}$ & Supported \\
\hline $\mathrm{H} 4$ & LI & $\rightarrow$ & CAA & 0.299 & 0.299 & 0.056 & $5.370 * * *$ & Supported \\
\hline H 5 & LS & $\rightarrow$ & CAA & 0.444 & 0.453 & 0.062 & $7.225^{* * *}$ & Supported \\
\hline H 6-1 & $\mathrm{CC}$ & $\rightarrow$ & CAA & 0.214 & 0.176 & 0.099 & 2.154 * & Supported \\
\hline H 6-2 & IN & $\rightarrow$ & CAA & 0.038 & 0.034 & 0.103 & 0.363 & Rejected \\
\hline H 6-3 & $\mathrm{EE}$ & $\rightarrow$ & CAA & 0.008 & 0.006 & 0.092 & 0.083 & Rejected \\
\hline
\end{tabular}

$\chi^{2}=569.7968(\mathrm{df}=258), p<0.001, \mathrm{CMIN} / \mathrm{DF}=2.209, \mathrm{RMR}=0.023 \mathrm{GFI}=0.914, \mathrm{AGFI}=0.892, \mathrm{NFI}=0.950, \mathrm{RFI}=0.942, \mathrm{IFI}=0.972$, $\mathrm{TLI}=0.967, \mathrm{CFI}=0.972$, RMSEA $=0.049$. Note: ${ }^{*} p<0.05,{ }^{* *} p<0.01,{ }^{* * *} p<0.001$.

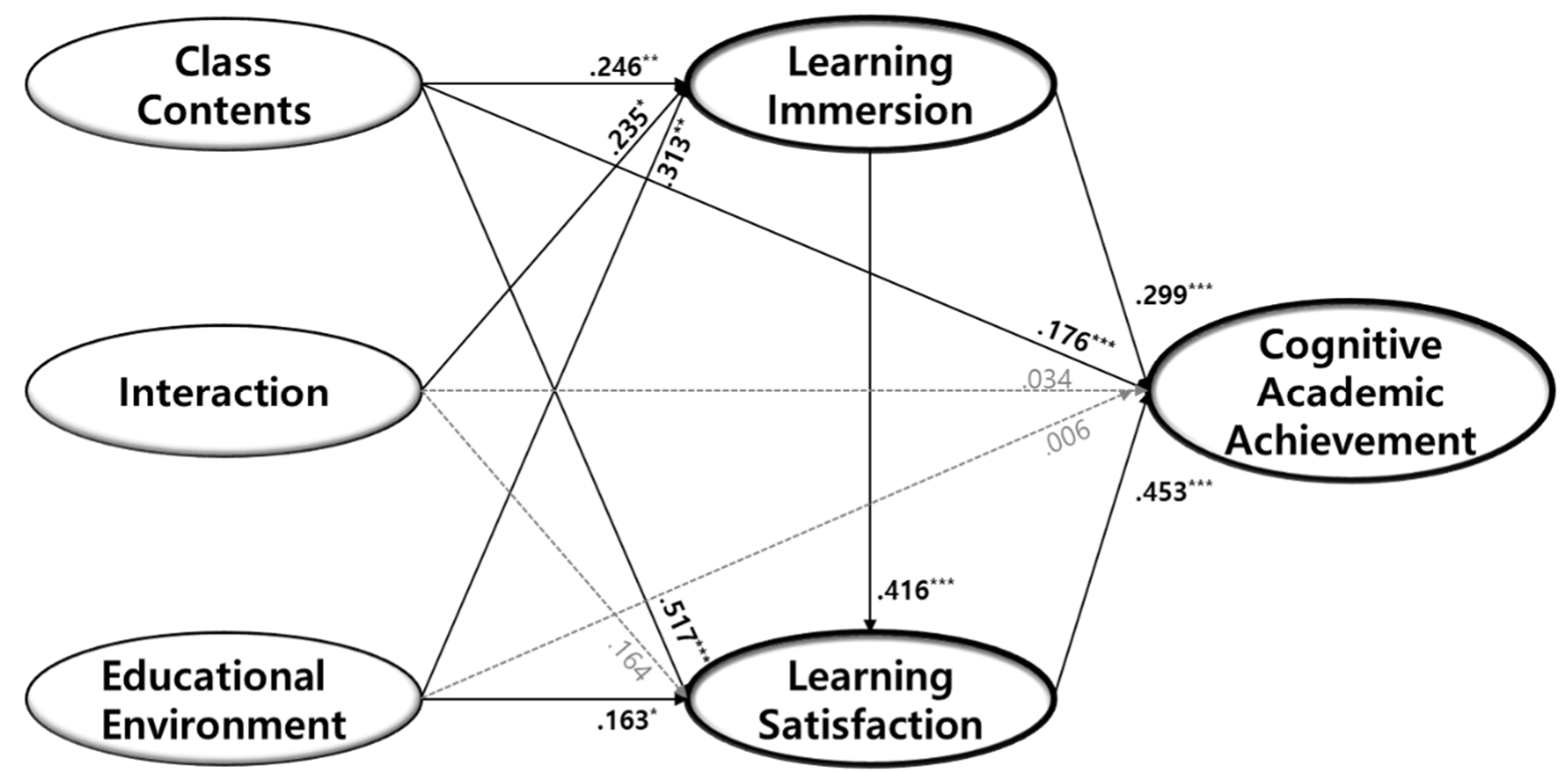

Figure 3. Results of SEM. Note: ${ }^{*} p<0.05,{ }^{* *} p<0.01,{ }^{* * *} p<0.001$.

As a result of the verification of Hypothesis 3, learning immersion $(\beta=0.416, t=8.197$, $p<0.001)$ was analyzed to have a positive $(+)$ effect on learning satisfaction. As a result of the verification Hypothesis 4 and 5, learning immersion $(\beta=0.299, t=5.370, p<0.001)$ and learning satisfaction $(\beta=0.453, t=7.225, p<0.001)$ positively influence academic achievement. Finally, as a result of the verification of Hypothesis 6 , it was analyzed that only class content $(\beta=0.176, t=2.154, p<0.05)$ among the quality of online classes had a positive $(+)$ influence on academic achievement $(\beta=0.034, t=0.363)$ and educational environment $(\beta=0.006, t=0.083)$ did not significantly affect academic achievement. Therefore, Hypothesis 1, Hypothesis 3, Hypothesis 4, and Hypothesis 5 were supported, and Hypothesis 2 and Hypothesis 6 were partially supported. 
In the hypothesis verification of this study, the effects of online class quality (class content, interaction, educational environment) on learning immersion, learning satisfaction, and academic achievement were shown to be different. Therefore, it is estimated that the class content has a partial mediating effect of learning immersion and learning satisfaction, interaction is completely mediated by learning immersion, and educational environment is completely mediated by learning immersion and learning satisfaction. Therefore, to verify the mediating effect of learning immersion and learning satisfaction in the relationship between online education quality and academic achievement, the significance of the mediation effect according to the $95 \%$ confidence interval of bootstrap was tested. The results of verification of the multiple mediation effect are shown in Table 6.

First, when confirming the mediating effect of learning satisfaction in the relationship between class content and academic achievement, there was no ' 0 ' between the lower and upper limits of the $95 \%$ confidence interval (0.191 0.550), so the mediating effect was found to be significant. The indirect effect showed an estimated value of 0.284 .

In the multiple mediating effect, which mediates learning immersion and learning satisfaction, the mediating effect was found to be significant because there was no ' 0 ' between the lower and upper limits of the $95 \%$ confidence interval (0.002 to 0.114 ), and the indirect effect showed an estimated value of 0.056 . In addition, significance was verified in the direct effect of class content on academic achievement, and it was confirmed that mediation by learning satisfaction, learning immersion, and multiple mediation by learning satisfaction had a partial mediation effect.

Table 6. Results of Mediation Effect.

\begin{tabular}{|c|c|c|c|c|c|c|}
\hline \multirow{2}{*}{ Path } & \multicolumn{2}{|c|}{ Estimate } & \multirow{2}{*}{ S.E. } & \multicolumn{2}{|c|}{ 95\% Confidence Interval } & \multirow{2}{*}{ Result } \\
\hline & B & $\beta$ & & LLCI & ULCI & \\
\hline $\mathrm{CC} \rightarrow \mathrm{LI} \rightarrow \mathrm{CAA}$ & 0.090 & 0.074 & 0.047 & -0.004 & 0.194 & - \\
\hline $\mathrm{CC} \rightarrow \mathrm{LS} \rightarrow \mathrm{CAA}$ & $0.284^{* *}$ & 0.234 & 0.074 & 0.191 & 0.550 & Partial Mediation \\
\hline $\mathrm{CC} \rightarrow \mathrm{LI} \rightarrow \mathrm{LS} \rightarrow \mathrm{CAA}$ & $0.056 *$ & 0.046 & 0.029 & 0.002 & 0.114 & Partial Mediation \\
\hline $\mathrm{IN} \rightarrow \mathrm{LI} \rightarrow \mathrm{CAA}$ & 0.078 & 0.070 & 0.062 & -0.044 & 0.204 & - \\
\hline $\mathrm{IN} \rightarrow \mathrm{LS} \rightarrow \mathrm{CAA}$ & -0.082 & -0.074 & 0.062 & -0.261 & 0.010 & - \\
\hline $\mathrm{IN} \rightarrow \mathrm{LI} \rightarrow \mathrm{LS} \rightarrow \mathrm{CAA}$ & 0.049 & 0.044 & 0.037 & -0.017 & 0.135 & - \\
\hline $\mathrm{EE} \rightarrow \mathrm{LI} \rightarrow \mathrm{CAA}$ & $0.113^{*}$ & 0.094 & 0.059 & 0.004 & 0.247 & Complete Mediation \\
\hline $\mathrm{EE} \rightarrow \mathrm{LS} \rightarrow \mathrm{CAA}$ & 0.089 * & 0.074 & 0.049 & 0.010 & 0.192 & Complete Mediation \\
\hline $\mathrm{EE} \rightarrow \mathrm{LI} \rightarrow \mathrm{LS} \rightarrow \mathrm{CAA}$ & $0.071 *$ & 0.059 & 0.034 & 0.016 & 0.155 & Complete Mediation \\
\hline
\end{tabular}

Note: ${ }^{*} p<0.05,{ }^{* *} p<0.01$.

Second, as a result of verifying the mediating effect of learning satisfaction and learning immersion in the relationship between interaction and academic achievement, significance was not verified in all paths.

Third, in the relationship between educational environment and academic achievement, the mediating effect of learning immersion and learning satisfaction was confirmed. When confirming the mediating effect of learning immersion, the mediating effect was found to be significant because there was no ' 0 ' between the lower and upper limits of the $95 \%$ confidence interval ( 0.004 to 0.247 ), and the indirect effect was estimated at 0.113 . As a result of confirming the mediating effect of learning satisfaction, the mediating effect was significant because there was no ' 0 ' in the $95 \%$ confidence interval lower limit and upper limit (0.010 0.192), and the indirect effect showed an estimated value of 0.089 .

Finally, in the multiple mediation effect by learning immersion and learning satisfaction, the mediating effect was significant because there was no ' 0 ' in the $95 \%$ confidence interval lower limit and upper limit (0.016 0.155), and the indirect effect was an estimated value of 0.071 . In addition, the hypothesis verification showed that the direct effect of the educational environment on academic achievement was not significant, and it was confirmed that all three mediating paths had a completely mediated effect. 


\section{Discussion}

Due to COVID-19, most higher educational institutions have pivoted from face-to-face lectures into online lectures, causing confusion for both instructors and learners. In particular, cooking-related subjects that require skill mastery through practical training have many limitations in achieving learning goals only through online education. Accordingly, this study aims to identify the problems of online education from the learner's perspective, suggesting ways to improve individual learning satisfaction and educational performance through segmentation of students. The structural impact relationship on learning satisfaction and the cognition of achievement felt by learners was confirmed. The results of this study are summarized as follows.

First, among the quality of online classes, the quality of class content had a significant influence on immersion, satisfaction, and achievement, and the educational environment had a positive (+) effect on immersion and satisfaction. The direct effect of online class quality on academic achievement was found to have a positive $(+)$ effect on class content.

These results showed a difference in the degree of influence, but it was consistent that the class content factor showed the greatest influence on satisfaction and academic achievement $[25,26,57,58]$. On the other hand, among the class quality of e-learning, lecture content and lecture quality do not have a significant influence on learning immersion, and unlike the study of Kim, Shin, and Kim [29], who argued that interaction quality had the greatest influence on academic achievement. contradictory results.

Second, learning immersion was found to have a positive (+) effect on learning satisfaction. This was found to be consistent with the research results of Kim and Park [63], Choi, Yeo, and Jeong [64], Lee, Kim, and Lee [65]. This indicated that learning immersion in online classes is an important influencing factor for improving learning satisfaction. In addition, learning immersion and learning satisfaction showed a positive influence on academic achievement. This result supported the studies of Kim and Park [33], Kim [10], but studies by Joo, Ha, Yoo, and Kim [71], Lee and Seo [31], show that there is no relationship between learning satisfaction and academic achievement, which is the opposite result.

Third, to verify the mediating effect of learning immersion and learning satisfaction on the relationship between online education quality and academic achievement, the significance of the mediating effect was tested according to the bootstrap 95\% confidence interval. As a result, it was found that there was a partial mediation effect on the simple mediation by learning satisfaction and the multiple mediation through learning immersion and learning satisfaction in the course, where the content of the online classes influences academic achievement. Comparing the direct and the indirect effect, the simple mediation path by learning satisfaction showed the greatest influence. In addition, in the relationship between educational environment and academic achievement, significance was verified in both the mediation of learning immersion, the mediation of learning satisfaction, and the multiple mediation of learning immersion and learning satisfaction. Therefore, it was found that the direct effect was not significant, confirming that there was a complete mediation effect in all indirect paths, and as a result of comparing the path values, the indirect effect through learning immersion was found to be the greatest. These results support the research results of Kim and Park [33], which mediate learning satisfaction, and the research results of Kim, Shin, and Kim [29], Choi and Ahn [35], which mediate learning immersion.

The implications based on the results of this study are as follows.

First, academic achievement and learning satisfaction were measured as indicators for judging the performance of online classes in culinary courses, and there is academic value in applying the information system success model proposed by Delone and Mclean [24] to explore the factors affecting learning performance. In addition, it is possible to indirectly grasp the performance of online cooking education by verifying the influence of educational performance factors based on the learner's subjective perception, and present empirical data to prepare for a post-COVID-19 future. Lastly, in the context of limited research on online classes in practical subjects, there is an academic significance of verify- 
ing its influence through empirical research on the quality of online instruction, learning immersion, learning satisfaction, and academic achievement.

Second, among the factors of class quality, class content showed the greatest influence on achievement and learning satisfaction. In other words, in the online cooking class, the content of the class was found to be important among the class quality as a factor that improves the learner's achievement and satisfaction. Therefore, when conducting a cooking practice class online, it is necessary to pay more attention to the learning materials so that a clear educational goal can be presented and self-directed learning can be achieved rather than face-to-face lessons. Rather than just showing the video, it is necessary to proceed in the direction of solving the curiosity of online lectures by providing detailed explanations and various examples according to the learner's level. In order to improve the academic achievement perceived by the learner, it is necessary to simultaneously satisfy the learner's psychological satisfaction and positive emotions, as well as the quality of learning materials and class content.

Third, among the factors of class quality, interaction showed the lowest effect on learning commitment, and did not have a significant influence on learning satisfaction and academic achievement. This is similar to the result of Lim, Park, and Park [59]'s study on the relationship between quality and satisfaction of culinary education service, in which responsiveness and empathy among service quality factors are not significant. In addition, the importance of interaction was relatively low due to non-real-time online education. Interactivity can predict to what extent online education can replace face-to-face classes [3], and the fact that no significant results are shown, even though it is an important factor for evaluating the results of education, implies a limitation of non-real-time online education.

Therefore, in the case of culinary education, real-time online education is considered to be more suitable to improve learning satisfaction and academic achievement, and when non-real-time online education is conducted, it is suggested that counseling and communication time for students outside of class hours are provided. In addition, the communication between the instructor and the learner is judged to have no significant effect on the satisfaction of the learner because the accessibility and responsiveness are inferior compared to the existing face-to-face classes. In particular, in the case of cooking practice subjects, learning through physical behavior is common, but in the case of online classes, the importance of interaction is thought to be low because actual experience is not possible. Therefore, the online cooking class does not place much emphasis on interactivity, but it is considered that immediate feedback and processing of requirements should be performed as an additional means to improve satisfaction.

Fourth, among the factors of class quality, online education environment was verified as a major factor in improving learning immersion and learning satisfaction. On the other hand, there was no direct influence on academic achievement, but indirect effects using mediation showed influence. In particular, when mediating learning immersion, its influence was found to be the greatest. In other words, it was confirmed that the quality of the educational environment is also an important variable in improving learners' achievement. Therefore, in the university, it is necessary to constantly check the system and build a large-capacity server so that all learners can access the program easily, and they will have to do their part in developing and equipping various programs so that instructors can select programs that are convenient to use. In addition, it is necessary for the instructor to check the online system and the quality of the video before class, and it is considered that familiarization should be preceded.

Despite providing the above practical implications, the limitations of this study are as follows.

First, there is a lack of generalization of all culinary students by selecting nonprobabilistic sampling. Second, the quality of online education was analyzed for the cooking practice subject, but the research was limited in the part that used the scale suitable for the theory class. Third, online education has limitations in generalizing online education in that different tools and systems are applied for each school and for each major. Based 
on the implications and limitations suggested by the researcher, the following studies are considered necessary.

Second, there is a need to compare and analyze the satisfaction and academic achievement of face-to-face practice classes and online lectures, and a comparative study on real-time education and non-real-time education in online education is considered to be necessary. Lastly, it is necessary to investigate factors that influence quantitative indicators such as credits, practical evaluation results, and acquisition of related qualifications, not subjective academic performance perceived by learners.

Author Contributions: Conceptualization, Y.-J.K. and S.-H.L.; methodology, Y.-J.K. and S.-H.L.; formal analysis, Y.-J.K. and S.-H.L.; writing-original draft preparation, Y.-J.K. and S.-H.L.; writingreview and editing, Y.-J.K. and S.-H.L. All authors have read and agreed to the published version of the manuscript.

Funding: This research received no external funding.

Institutional Review Board Statement: Not applicable.

Informed Consent Statement: Not applicable.

Data Availability Statement: Not applicable.

Conflicts of Interest: The authors declare no conflict of interest.

\section{References}

1. Kim, S.H.; Cheon, S.M. A Case Study of Online Class Operation and Instructor's Difficulties in Physical Education as a Liberal Arts in University Due to COVID-19. J. Sports Leis. Studi. 2021, 81, 9-26. [CrossRef]

2. Dhawn, S. Online learning: A panacea in the time of COVID-19 crisis. J. Educ. Technol. Syst. 2020, 49, 5-22. [CrossRef]

3. Garrison, D.R. E-Learning in the 21st Century: A Community of Inquiry Framework for Research and Practice; Routledge: New York, NY, USA, 2016.

4. Eom, S.B.; Wen, H.J.; Ashill, N. The determinants of students' perceived learning outcomes and satisfaction in university online education: An empirical investigation. Dec. Sci. J. Innov. Educ. 2006, 4, 215-235. [CrossRef]

5. Zhang, J.; Zhu, H.Q.; Kim, B.K. Effects of the Amount of Images in Video Learning Has on Learning Satisfaction and Academic Achievement of Chinese University Students, Focusing on Their Learning Styles. Korean J. Converg. Humanit. 2020, 8, $23-44$.

6. Jang, W.H.; Choi, M.J.; Hong, H.G. A case study on the operation of non-face-to-face experimental class at university with Covid-19 pandemic. J. Learn. Cent. Cur. Inst. 2020, 20, 937-966. [CrossRef]

7. Bae, S.Y.; Chang, P.J. The effect of coronavirus disease-19 (COVID-19) risk perception on behavioural intention towards 'untact' tourism in South Korea during the first wave of the pandemic. Curr. Issues Tour. 2020, 24, 1017-1035. [CrossRef]

8. Park, J.Y. A Study on the Online Education of Universities Promoted by COVID-19. J. KSME 2020, 60, 32-36.

9. Lee, E.J.; Zae, S.J.; Youn, H.S. Exploring the difficulties and strategies of practicing online classes experienced by high school veteran physical education teachers in the Corona19 Pendemic. J. Digit. Converg. 2020, 20, 339-362. [CrossRef]

10. Kim, Y.M. The Effects of Social Presence on Learning Satisfaction and Learning Achievement in Cyber University. e-Bus. Stud. 2019, 20, 199-216. [CrossRef]

11. Lee, H.Y.; Jeong, H.S. A study on the difference of primary language use and level of proficiency in interactive synchronous online Korean language classes. J. Inter. Net. Korean Lang. Cult. 2020, 17, 129-150. [CrossRef]

12. Lim, J.E.; Lee, M.H. Effects of online learners' presence perception on academic achievement and satisfaction mediated by self-efficacy for self-regulated learning and agentic engagement. Korean J. Educ. Meth. Stud. 2020, 32, 461-485.

13. Lee, Y.H.; Park, Y.J.; Yun, J.H. Exploring the "Types" through Case Analysis on Operation of Distance Education in Universities Responding to COVID-19. J. Yeolin Educ. 2020, 28, 211-234. [CrossRef]

14. Jeong, C.G.; Yun, J.S. Online Real time Lecture Operation Examples and Training Effects: Focusing on the Case of at Korea University. Korean J. Conv. Humanit. 2020, 8, 159-179.

15. Jung, H.Y.; Yoon, J.W. A Survey Research of Student's Perception of Korean Language Online Video Lecture. J. Humanit. Soc. Sci. 2020, 11, 1305-1318.

16. Bainbridge, W.S. Berkshire Encyclopedia of Human-Computer Interaction. (Vol. 1); Berkshire Publishing Group LLC: Great Barrington, MA, USA, 2004.

17. Lee, S.C.; Kim, J.A. Factors that affect student satisfaction with online courses. J. Educ. Admin. 2018, 36, 115-138. [CrossRef]

18. Anderson, T. (Ed.) The Theory and Practice of Online Learning; Athabasca University Press: Edmonton, AB, Canada, 2008.

19. Cojocariu, V.M.; Lazar, I.; Nedeff, V.; Lazar, G. SWOT analysis of e-learning educational services from the perspective of their beneficiaries. Proc. Soc. Behav. Sci. 2014, 116, 1999-2003. [CrossRef]

20. Singh, V.; Thurman, A. How many ways can we define online learning? A systematic literature review of definitions of online learning (1988-2018). Am. J. Distance Educ. 2019, 33, 289-306. [CrossRef] 
21. Choi, J.S.; Kwon, M.K.; Choi, E.K. A Study on the Instructor Perceptions and Satisfaction levels of Real-time Online Classes: Focusing on the case of Korean language program at D University. J. Dong-ak Lang. Lit. 2020, 81, 135-168.

22. Lee, E.J.; Park, I.W. Identifying Predictability of Computer Self-Efficacy, Teaching Presence and Learner Participation on Learner Satisfaction in Online Realtime Instruction. J. Yeolin. Educ. 2012, 20, 195-219.

23. Skylar, A. A comparison of asynchronous online text-based lectures and synchronous interactive web conferencing lectures. Issu. Teach. Educ. 2009, 18, 69-84.

24. Delone, W.H.; McLean, E.R. The DeLone and McLean model of information systems success: A ten-year update. J. Manag. Inf. Syst. 2003, 19, 9-30.

25. Lee, J.Y.; Lee, E.J. Influence analysis of system, information and service qualities on learner satisfaction in university e-learning. J. Educ. Stud. 2010, 41, 119-147.

26. Chei, M.J.; Lee, J.Y. Analysis of Structural Relationship among Instructional Quality, Academic Emotions, Perceived Achievement and Learning Satisfaction in Offline and Online University Lectures. Korean Assoc. Educ. Inf. Media 2017, $23,523-548$.

27. Ko, J.W.; Kim, H.J.; Kim, M.S. The impact of students' college experiences on students' cognitive and non-cognitive outcomes, and instructional satisfaction. J. Educ. Admin. 2011, 29, 169-194.

28. Jeong, E.I. Relations among Class disturbing factors perceived by college students and professors, class participation, and class satisfaction. Korea Educ. Rev. 2012, 18, 73-103.

29. Kim, Y.A.; Shin, H.K.; Kim, J.W. A Study on the Influence of System Quality and Synchronization Factors for Learning Performance in e-Learning: The Mediating Effect of Learning Flow. J. Inf. Syst. 2011, 20, 181-204.

30. Lee, J.Y.; Kim, S.W.; Kim, J.R. Analysis of quality factors influencing learner satisfaction on mobile learning linked to e-learning in universities. J. Educ. Technol. 2013, 29, 209-240. [CrossRef]

31. Lee, J.Y.; Seo, J.T. Analysis of the Structural Relationships among Instructional Quality Factors, Learning Satisfaction, and Academic Achievement. Asia-Pac. J. Mult. Serv. Conv. Art. Hum. Soc. 2017, 7, 135-144. [CrossRef]

32. Kim, D.S.; Lee, Y.S. Difference of Information Quality, Service Quality, System Quality and Satisfaction between University Students and the General Public in MOOC. J. Lifelong Learn. Soc. 2018, 14, 83-103. [CrossRef]

33. Kim, S.Y.; Park, I.W. The Structural Relationship among Intention to Take, Quality, Learning Satisfaction, Achievement and Continued to Use Intention in K-MOOC Learning Environment. J. Educ. Inf. Med. 2019, 25, 525-549.

34. Kim, S.M. Analysis of Press Articles in Korean Media on Online Education related to COVID-19. J. Digit. Contents Soc. 2020, 21, 1091-1100. [CrossRef]

35. Choi, W.S.; Ahn, G.Y. The Effects of Learning Service Quality and Interaction of Uncontact Learning in College of Culinary \& Food Service on Learning Immersion and Learning Achievement. Culin. Sci. Hosp. Res. 2020, 26, 12-26.

36. Csikszentmihalyi, M. Play and intrinsic rewards. In Flow and the Foundations of Positive Psychology; Springer: Dordrecht, The Netherlands, 1975.

37. Csikszentmihalyi, M.; Jeanne, N. The dynamics of intrinsic motivation: A study of adolescents. In Flow and the Foundations of Positive Psychology; Springer: Dordrecht, The Netherlands, 2014; pp. 175-197.

38. Csikszentmihalyi, M.; Flow, M. The Psychology of Optimal Experience; Harper \& Row: New York, NY, USA, 2008.

39. Bolliger, D.U. Key factors for determining student satisfaction in online courses. Int. J. E-Learn. 2004, 3, 61-67.

40. Marks, H.M. Student engagement in instructional activity: Patterns in the elementary, middle and high school years. Am. Educ. Res. J. 2000, 37, 153-184. [CrossRef]

41. Coates, H. Student Engagement in Campus-Based and Online Education; Routledge: New York, NY, USA, 2006.

42. Lee, E.K. Effects of students' flow and cognitive Learning engagement on their Learning outcomes in online Learning. J. Korean Assoc. Educ. Inf. Med. 2011, 17, 379-397.

43. Garrison, D.; Anderson, T.; Archer, W. Critical inquiry in a text-based environment. Internet High. Educ. 2000, 2, 87-105. [CrossRef]

44. Oliver, R.L. A cognitive model of the antecedents and consequences of satisfaction decisions. J. Mark. Res. 1980, 17, 460-469. [CrossRef]

45. Elliot, K.M.; Healy, M.A. Key factors influencing student satisfaction related to recruitment and retention. J. Mark. High. Educ. 2001, 10, 1-11. [CrossRef]

46. Astin, A.W. The changing American college student: Implications for educational policy and practice. High. Educ. 1991, 22, 129-143. [CrossRef]

47. Shin, N.M.; Chan, J. Direct and indirect effects if inline learning in distance education. Br. J. Educ. Technol. 2004, 35, 275-288. [CrossRef]

48. Kim, J.S.; Kang, M.H. Structural relationship among teaching presence, learning presence, and effectiveness of e-learning in the corporate setting. Asian J. Educ. 2010, 11, 29-56.

49. Lee, J.Y. Effects of self-direction, prior knowledge and delivery strategies on learner satisfaction and performance in Web-based instruction. J. Educ. Technol. 2002, 18, 3-25. [CrossRef]

50. Park, J.Y. The effects of university students' self-directed learning ability and perceived online task value on learning satisfaction and academic achievement. Eng. Lang. Teachnol. 2017, 29, 165-185.

51. Choi, M.; Han, T.I. A study on the variables influencing student achievement in a blended learning of college English. J. Dig. Converg. 2013, 11, 719-730. 
52. Rouiller, J.Z.; Goldstein, I.L. The relationship between organizational transfer climate and positive transfer of training. Hum. Resour. Dev. Q. 1993, 4, 377-390. [CrossRef]

53. Kim, S.H.; Chung, O.B. A Study on the perception and the satisfaction with learning on human development and family relations area of the 6th revision of middle school Home Economics Education curriculum. J. Korean Home Econ. Educ. Assoc. 1997, 9, 47-67.

54. Rovai, A.P. Sense of community, perceived cognitive learning, and persistence in asynchronous learning network. Internet High Educ. 2002, 5, 319-332. [CrossRef]

55. Pace, C.R. The Undergraduates: A Report of Their Activities; Center for the Study of Evaluation, University of Columbia: Los Angeles, CA, USA, 1990.

56. Jeon, J.S.; Kim, S.Y. Validating an evaluation model to measure the effectiveness of educational programs of lifelong education centers affiliated with universities. Culi. Sci. Hosp. Res. 2011, 42, 125-150.

57. Kim, H.J.; Roh, S.Z.; Yu, B.M. The Effects of Learner Characteristics, Teaching Presence, and Content Quality on Learning Effects in the General University e-Learning: Focused on the Mediating Effect of Learning Flow. J. Educ. Res. 2015, 13, 171-194.

58. Ahn, H.R.; Shin, H.C. A Study on the Influence of Non-face-to-Face Education Service Quality on Learning Commitment and Education Satisfaction: Focused on Students Majoring in Tourism. J. Tour. Leis. Res. 2020, 32, 363-384.

59. Lim, S.H.; Park, K.Y.; Park, A.S. The Effects of Cooking Education Service Quality on Satisfaction of Adult Learners of Lifelong Education Center. J. Foodserv. Manag. Soc. Korea 2017, 20, 289-307.

60. Kim, H.K.; Choi, S.H.; Ma, Z. The Mediation Effects of Learner's Satisfaction on the Influence of Education Service Quality Perceived by Vocational Training Institute Students Major of Culinary on Learning Transfer. Tour. Res. 2020, 45, 141-164.

61. Kim, T.U.; Um, M.Y. Gender Differences in Perceptions and Relationships among Determinants of User Satisfaction in e-Learning. Korean Manag. Rev. 2006, 35, 51-80.

62. Huh, Y.J. The Effects of Contents Quality Factors on Academic Persistence in Online Education Responding to COVID-19: Focused on the Mediating Learning Flow and Satisfaction. J. Know. Inf. Technol. Syst. 2020, 15, 759-770.

63. Kim, U.J.; Park, J.H. The Relationships among Learning Presence, Learning Flow, and Academic Achievement at the Cyber Universities. Asian J. Educ. 2012, 13, 143-170.

64. Choi, K.H.; Yeo, H.K.; Jeong, H.K. The effect of Learning Motivation and Academic Self-Efficacy of University Students Majoring Tourism on Learning Flow, Academic Achievement and Learning Transfer. J. Tour. Leis. Res. 2014, 26, 451-469.

65. Lee, J.G.; Kim, W.J.; Lee, J.K. The relationship between learning motivation, learning commitment and academic achievement of nursing students who gave non-face-to-face online lectures. J. Korea Acad.-Ind. Coop. Soc. 2020, 21, 412-419.

66. Barzilai, S.; Blau, I. Scaffolding game based learning: Impact on learning achievements, perceived learning, and game experiences. Comput. Educ. 2014, 70, 65-79. [CrossRef]

67. Lee, S.H.; Seo, J.H.; Lee, J.H. The influence of the educational environment of the cooking institute on the educational satisfaction and the behavior intention: Moderating effect of educational period. Culin. Sci. Hosp. Res. 2017, 23, $194-203$.

68. Lee, S.H. Verification of structural relationship between quality of Untact online education, academic achievement, and learning satisfaction to prepare for Post COVID. J. Foodserv. Manag. 2020, 23, 229-252.

69. Hair, J.F.; Anderson, R.E.; Tatham, R.L.; Black, W.C. Multivariate Data Analysis; Prentice-Hall: Englewood Cliffs, NJ, USA, 1998.

70. Fornell, C.; Larcker, D.F. Evaluating structural equation models with unobservable variables and measurement error. J. Market. Res. 1981, 18, 39-50. [CrossRef]

71. Joo, Y.J.; Ha, Y.J.; Yoo, J.W.; Kim, E.K. The Structural Relationship among Teaching Presence, Cognitive Presence, Social Presence, and Learning Outcome in Cyber University. J. Korean Assoc. Inf. Educ. 2010, 14, 175-187. 